\title{
O STF E AS BASES MATERIAIS PARA A HERMENÊUTICA TRANSCONSTITUCIONAL
}

\section{BRAZILIAN SUPREME FEDERAL COURT (STF) AND THE MATERIAL BASES FOR TRANSCONSTITUCIONAL HERMENEUTICS}

\author{
${ }^{1}$ Ramaís de Castro Silveira \\ ${ }^{2}$ Roberta Camineiro Baggio
}

\section{RESUMO}

O artigo versa sobre condições brasileiras, notadamente do Supremo Tribunal Federal (STF), para a aplicação do transconstitucionalismo. Inicia-se por conceituar o transconstitucionalismo com base na obra da Marcelo Neves. Na sequência, são analisadas as condições criadas pelo STF de divulgação das decisões constitucionais de outros países. De outro lado, é verificada a disposição do STF ao diálogo constitucional com base em duas ações de grande repercussão (ADPF $\mathrm{n}^{\circ} 153$ e AP $\mathrm{n}^{\circ}$ 470). A partir das análises, se conclui que o Brasil parece muito disposto a conhecer decisões e pouco propenso a abrir-se hermeneuticamente ao diálogo constitucional.

Palavras-chave: Transconstitucionalismo, Supremo tribunal federal, Condições de efetivação

\begin{abstract}
The paper is about Brazilian conditions, especially those of the Supreme Federal Court (STF), for the application of transconstitucionalism. It begins by conceptualizing the transconstitucionalism based on the work of Marcelo Neves. Further, the conditions created by the STF for dissemination of constitutional decisions of other countries are analyzed. On the other hand, the willingness of the STF to the constitutional dialogue is verified based on two highly publicized actions (ADPF 153 and AP 470). From the analysis, it is concluded that Brazil seems very willing to know decisions and disinclined to open up hermeneutically to the constitutional dialogue.
\end{abstract}

Keywords: Transconstitucionalism, Supreme federal court, Effectiveness conditions

\footnotetext{
${ }^{1}$ Doutor em Direito Universidade de Brasília - UnB (Brasil). Professor de Direito do Instituto Federal do Rio Grande do Sul - IFRS, Rio Grande do Sul (Brasil). E-mail: ramaisdecastro@uol.com.br

${ }^{2}$ Doutora em Direito pela Universidade de Santa Catarina - UFSC (Brasil). Professora da Faculdade de Direito da Universidade Federal do Rio Grande do Sul - UFRGS, Rio Grande do Sul (Brasil). E-mail: robertabaggio@uol.com.br
} 


\section{INTRODUÇÃO}

O trabalho que segue-se utiliza como base teórica o diálogo constitucional de âmbito transnacional, tal qual desenvolvido na obra de Marcelo Neves e também de Canotilho e Häberle. Estas teorias trazem como prisma de análise das experiências de trocas argumentativas entre judiciários nacionais, internacionais e transnacionais o pressuposto das trocas argumentativas horizontais, com juristas - e sobretudo juízes - buscando alcançar ou mesmo reforçar suas decisões sobre o sentido da Constituição e dos direitos fundamentais ali previstos com base nas experiências de seus colegas de outras partes.

Segue-se, no desenvolvimento, com a demonstração de que o Brasil vem, sobretudo via ação do Supremo Tribunal Federal (STF), produzindo um conjunto notável de parcerias e estruturas de interação jurisprudencial com os judiciários de países e grupos de países mundo afora. A variedade de protocolos, organizações e bases de dados que está disponível não tem paralelo na história brasileira, e permite que magistrados nacionais acessem os mais variados julgados, de basicamente todos os quadrantes do globo, acerca de direitos humanos.

Não obstante, é notável o quanto ainda há resistência, na prática hermenêutica do STF, à utilização dos mecanismos que a própria Corte viabiliza. Os ministros parecem utilizar pouco as fontes internacionais de jurisprudência, além de manifestarem, dentro e fora dos autos, certo grau de desconfiança e até mesmo desprezo sobre a força vinculante de julgados de instâncias como a Corte Interamericana de Direitos Humanos. O artigo explora essa contradição em casos como o da Ação Penal no 470 e da Ação de Descumprimento de Preceito Fundamental no 153, ambos julgados no plenário do Supremo.

A conclusão é de que vive-se no Brasil, ainda, uma contradição entre os meios disponíveis para o diálogo transconstitucional e a efetiva postura hermenêutica dos magistrados nacionais, sobretudo ministros do STF, no tocante ao debate argumentativo com a jurisprudência estrangeira.

\section{CONCEITO DE ANÁLISE DO DIÁLOGO CONSTITUCIONAL}

O transconstitucionalismo é novo no escopo (âmbito de aplicação - além dos clássicos, o transnacional e o local) e em determinados pressupostos (como as racionalidades transversais) e experienciado (mas não por isso menos atual) em determinados postulados (tais como a incapacidade dos Estados-Nação de lidar com alguns temas maiores - de segurança, ambientais, econômicos etc. $)^{1}$. 
O transconstitucionalismo parte da existência de uma sociedade mundial, que tem em sua intensificação o efeito comumente intitulado globalização (NEVES, 2009, p. 27). Ela não desemboca, como sistema, no acoplamento estrutural, no nível planetário, em uma Constituição Mundial, antes pelo contrário (NEVES, 2009, p. 31). A existência dessa sociedade mundial, com seu sistema econômico no nível estrutural, e sistema dos meios de comunicação em massa no nível semântico, de acordo com Neves:

[...] tornou praticamente imprescindível a emergência de uma "nova ordem mundial" concernente não só a processos de tomada de decisão coletivamente vinculante, mas também a mecanismos de estabilização de expectativas normativas e regulação jurídica de comportamentos. Isso significa uma transformação no sentido de uma contrapartida normativa à expansão dinâmica do momento cognitivo da sociedade (que é o sistema econômico) (NEVES, 2009, p. 31).

Contra o sentido de que a globalização teria sepultado o direito e a política dos Estados-Nação, Neves pretende uma

[...] análise que, sem desconhecer a emergência de novos atores, sistemas, "regimes" ou "redes" globais, com pretensão de tomar decisões coletivamente vinculantes e produzir normas jurídicas, leve em conta que o Estado ainda é foco fundamental da reprodução da nova ordem normativa mundial. [...] Antes, o que tem ocorrido é um entrelaçamento de ordens estatais, internacionais, supranacionais, transnacionais e locais no âmbito de um sistema jurídico mundial de níveis múltiplos, a partir do qual se tem desenvolvido o transconstitucionalismo na sociedade mundial (NEVES, 2009, p. 31).

A Constituição é o acoplamento estrutural entre o subsistema político e o jurídico, não havendo qualquer supremacia (ou subordinação) entre política e direito (NEVES, 2009, p. 58). Raciocinando a partir dos sistemas, pode-se dizer que o povo fecha o subsistema político e que a Constituição fecha o subsistema jurídico. Os reingressos e reentrâncias garantem abertura cognitiva dos sistemas nesse acoplamento estrutural, mas mais que isso, a Constituição é instância da relação recíproca e duradoura de aprendizado e intercâmbio de

\footnotetext{
${ }^{1}$ De acordo com Marcelo Neves: "As ordens estatais, internacionais, supranacionais, transnacionais e locais, consideradas como tipos específicos, são incapazes de oferecer, isoladamente, respostas complexamente adequadas a problemas normativos da sociedade mundial. [...] O transconstitucionalismo, como modelo de entrelaçamento que sirva à racionalidade transversal entre ordens jurídicas diversas, abre-se a uma pluralidade de perspectivas para a solução de problemas constitucionais, melhor adequando-se às relações entre ordens jurídicas do sistema jurídico heterárquico da sociedade mundial.” (NEVES, 2009, p. 131).
} 
experiências com as racionalidades particulares já processadas, respectivamente, na política e no direito. Isso envolve entrelaçamentos como "pontes de transição" entre ambos os sistemas, de tal maneira que pode desenvolver-se uma racionalidade transversal específica. Com a superação, a partir da teoria dos sistemas, da subordinação entre política e direito e a adoção da coordenação entre os subsistemas, está arado o terreno para o transconstitucionalismo.

Isto se dá, na medida em que a soberania de um sistema hierárquico se abre à coordenação com outros níveis de acoplamento estrutural ${ }^{2}$. O autor refuta as ideias de uma constituição supranacional global, mormente porque não se está em condições de falar seriamente em um Estado mundial. No nível comunitário, ou supranacional regional, a constituição seria viável se as desigualdades no desenvolvimento fossem superadas e houvesse, já no âmbito dos Estados-Nação, constituições transversais. Seria, ainda, necessário um povo constitucional determinante dos procedimentos no plano supranacional e uma esfera pública forte, que possa servir à abertura do sistema político. Estas condições todas, entretanto, não são ainda hoje observadas nem na União Europeia, o caso mais avançado no nível global (NEVES, 2009, p. 107). O autor, por fim, rechaça a emergência das constituições civis transnacionais como possíveis repositórios paraestatais de normas constitucionais subsistemáticas.

Afastadas as hipóteses de generalidade constitucional mundial, impõe-se o transconstitucionalismo, não mais com a necessária "intermediação política mediante tratados jurídico-internacionais, mas sim com 'pontes de transição' entre ordens jurídicas que desenvolvem-se diretamente a partir dos seus respectivos centros, ou seja, os seus juízes e tribunais" (NEVES, 2009, p. 116). Dessa maneira, para o centro de um determinado subsistema jurídico (tribunais) os demais subsistemas são a periferia, tomando o conceito de um mundo formado por um grande sistema jurídico multicêntrico. E, para Neves, “[...] essa situação importa relações de observação mútua, no contexto da qual se desenvolvem formas de aprendizado e intercâmbio, sem que se possa definir o primado de uma das ordens, uma ‘ultima ratio’ jurídica” (NEVES, 2009, p. 116). Há um diálogo entre Cortes, uma comunicação transversal que perpassa fronteiras entre ordens jurídicas, mas que sempre terá a tendência do conflito e da disputa. Existe, também, a incorporação de normas de outra ordem

\footnotetext{
${ }^{2}$ Marcelo Neves destaca que, nessa situação, "O que intriga a 'ciência' jurídica tradicional é a pretensão dessas novas ordens jurídicas de se afirmarem impreterivelmente, seja como ordens jurídicas que prescindem do Estado, seja como ordens jurídicas que prevalecem contra os Estados, pondo em cheque o próprio princípio da soberania estatal, viga mestra do direito internacional público clássico" (NEVES, 2009, p. 83).
} 
sem a intermediação dos tribunais, neste caso por meio da reinterpretação da própria ordem a partir de sentidos de subsistemas externos.

A grande mudança do transconstitucionalismo é colocar nessas trocas uma relação de bilateralidade, numa verdadeira conversa, em que há desconstrução do outro e autodesconstrução. Mais do que adstringir-se a um determinado subsistema para saber-se o que são as matérias constitucionais, agora é necessário dizer quais problemas constitucionais exigem “[...] soluções fundadas no entrelaçamento entre ordens jurídicas. O que caracteriza o transconstitucionalismo relativo a ordens jurídicas é, portanto, ser um constitucionalismo relativo a (soluções de) problemas jurídico-constitucionais que se apresentam simultaneamente a diversas ordens.” (NEVES, 2009, p. 129). Também é relevante perceber que "[q]uando questões de direitos fundamentais ou de direitos humanos submetem-se ao tratamento jurídico concreto, perpassando ordens jurídicas diversas, a 'conversação' constitucional é indispensável” (NEVES, 2009, p. 129).

\section{AS CONDIÇÕES MATERIAIS NO BRASIL}

O transconstitucionalismo, tal como é definido acima, consubstancia-se nos marcos do que se pode chamar de teoria do diálogo constitucional, assim como nesse bojo se colocam, por exemplo, as ideias de Peter Häberle acerca do Estado Constitucional Cooperativo (2007) e José Canotilho (2008) quando trata de sua interconstitucionalidade. É certo, contudo, que uma a vertente de críticas que se pode sentir a tais abordagens calça-se no argumento de que são teorias apenas bem intencionadas, havendo pouco de força vinculante em seus pressupostos. Em outras palavras: os diálogos constitucionais somente ocorreriam quando e onde encontrassem atores dispostos a efetivá-los.

É possível que tais críticas se fundamentem na premissa de que o transconstitucionalismo é uma teoria normativa, algo que parece longe de seu escopo. Se nos parece que, antes disso, ele busca perceber um movimento fático, que ocorre nas trocas, nas racionalidades transversais efetivamente existentes, produzidas por iniciativas humanas intencionadas à resolução de problemas jurídicos concretos, e notadamente os de Direitos Humanos.

Produzir tais entrelaçamentos comunicativos, contudo, não é tarefa simples, ainda para quem o queira. Há elementos que a nova tecnologia da informação tem entregue recentemente ao Direito, permitindo agilidade e fluidez de trocas de informações, não restando dúvidas de que a internet é o veículo privilegiado deste tráfego de ideias. Isto tem permitido que um sem 
número de decisões de Tribunais e artigos científicos que as abordam percorram o mundo nos seus mais diversos quadrantes, e o melhor, dentro de um período relativamente curto de tempo a contar da data de suas lavras e prolações.

Alguns Tribunais e sistemas jurídicos começam a criar ferramentas para permitir que seus julgados sejam conhecidos além das fronteiras nacionais, como é o caso do Supremo Tribunal Federal brasileiro, que com isso passa a garantir acesso, inclusive em idioma estrangeiro, de julgados sobre casos paradigmáticos. Se tal iniciativa é válida por permitir que a experiência jurídica do Brasil possa ser mais facilmente conhecida, e até utilizada em outros lugares, também o país tem tido recentemente oportunidades de abrir seu sistema a soluções pretéritas de outras esferas jurídicas. São estes dois aspectos, disponibilidade brasileira de sua experiência e abertura nacional à influência externa que se abordará neste trabalho, tendo por base o conjunto de elementos que conformam a teoria do transconstitucionalismo conforme inicialmente apontado. A tarefa será desempenhada com foco, em ambos os casos, no STF, conforme a seguir, onde se analisará, com brevidade, os impactos da Ação de Descumprimento de Prefeito Fundamental (ADPF) nº 153 e Ação Penal (AP) no 470.

\subsection{Mecanismos de trocas}

Um conjunto de ações de cooperação internacional vem sendo operado pelo Brasil, capitaneado pelo STF, com o sentido de viabilizar canais de interação sobre experiências jurisdicionais. O primeiro braço destas ações diz com os pactos que conformam organizações multilaterais com fins de integração; um segundo é aquele diretamente vinculado à disponibilização de jurisprudências.

Quanto ao primeiro, temos a Conferência das Jurisdições Constitucionais dos Países de Língua Portuguesa - CJCPLP, uma organização que nasce da ação dos Tribunais destes países ${ }^{3}$ com o fim de permitir representação comum em fóruns internacionais e ser um canal de trocas de experiências acerca de controle de constitucionalidade (STF, 2016). Inicia-se no ano de 2008 com a declaração de intenções das Cortes dos países de língua portuguesa, culminando em 2010 com a realização da primeira assembleia geral. É remarcável que os

Estatutos da organização reconheçam a progressiva importância das instituições com

\footnotetext{
${ }^{3}$ Integrada pelos Tribunais Constitucionais de Angola e de Portugal, o Supremo Tribunal Federal do Brasil, os Supremos Tribunais de Justiça de Cabo Verde, da Guiné-Bissau e de São Tomé e Príncipe, o Conselho Constitucional de Moçambique e o Tribunal de Recurso de Timor-Leste.
} 
jurisdição constitucional na promoção dos direitos humanos e na defesa da democracia e da independência judicial, tanto em nível interno, quanto internacional (STF, 2016). Com efeito, diz o Art. $2^{\circ}$ dos Estatutos:

Constituem objectivos da Conferência, designadamente: A promoção dos direitos humanos, a defesa da democracia e da independência judicial; Fomentar a cooperação e a troca de experiências referentes ao controlo da constitucionalidade; A realização de uma reunião plenária - denominada "Assembleia" - de dois em dois anos; Dinamizar o intercâmbio técnico entre as estruturas dos diferentes membros (STF, 2016).

A disponibilização de jurisprudências é feita por meio do Repositório de Jurisprudência Constitucional dos Países da Comunidade dos Países de Língua Portuguesa (CPLP) (STF, 2016). Nele é possível realizar pesquisas com palavras chave nas jurisprudências constitucionais de todos os países da CPLP, sendo que o link garante, também, acesso direto aos textos constitucionais de todos os integrantes. Já houve quatro assembleias da Conferência, a primeira em maio de 2010, na cidade de Lisboa; a segunda no mês em 2012, na cidade de Maputo, Moçambique ; a terceira, realizada no mês de junho de 2014, na cidade de Lobito, em Angola e a quarta realizada na cidade de Brasília em abril de 2016. Nestes eventos são apresentados relatórios das práticas dos Tribunais e Cortes Supremas, com menção a decisões paradigmáticas. A previsão é que a cada dois anos ocorram encontros desta natureza, com vistas à troca de experiências e aprofundamento da cooperação. Na segunda edição, o Brasil propôs e viu aprovada a proposição de um programa chamado Tobias Barreto, pelo qual será facilitada a visita ao STF, de magistrados dos países da Comunidade interessados em conhecer a jurisdição brasileira em matéria constitucional.

Outra organização da qual o Brasil participa via STF é o Fórum de Cortes Supremas do Mercosul, criado em 2004. Ele é integrado pelos Tribunais e Cortes Supremas dos Estados do Mercosul e associados. Estão entre as finalidades do Fórum, de acordo com o Art. $1^{\mathrm{o}}$ do seu Regimento Interno:

I - promover a cooperação dos Tribunais e das Cortes Supremas dos Estados Partes e Associados; II- participar de atividades que repercutam na melhoria e no desenvolvimento do ordenamento jurídico do MERCOSUL; III- manter intercâmbio com Cortes Supremas e Constitucionais de outros Estados e com tribunais de blocos econômicos regionais ou organizações supranacionais; IV- compartilhar informações sobre decisões jurisdicionais que contemplem normativa do MERCOSUL; V- estimular o estudo, a pesquisa e a disseminação do ordenamento jurídico do MERCOSUL; e VI - realizar e apoiar atividades culturais e científicas na área jurídica, notadamente na área do direito internacional e da integração (STF, 2016) 
Como se vê, trata-se de organização com finalidades semelhantes às da CJCPLP, tendo apenas um âmbito diverso. A 9 de novembro de 2007, firmou-se acordo de cooperação para o intercâmbio de informações e de publicações através da utilização de um banco de dados de jurisprudência do Mercosul. Com este acordo, ficou criado o banco de dados ${ }^{4}$ intitulado Jurisprudência dos Países do Mercosul, destinado a receber e armazenar os respectivos dados de jurisprudência constitucional das Cortes Supremas, bem como de decisões judiciais que tenham por objeto normas do Mercosul (Cláusula Segunda do Acordo) (STF, 2016).

O sítio principal do Fórum $^{5}$ traz a possibilidade de visualização dos textos constitucionais de todos os países membros, além de legislações dos mesmos sobre regulação da magistratura. As gravações de painéis de alguns dos encontros anuais do Fórum, bem como entrevistas de presidentes das Cortes também podem ser acessadas. É de âmbito do Fórum, com inegável protagonismo do Brasil, o acordo de implantação e execução do Programa de Estímulo à Cooperação e ao Intercâmbio na área do Direito no Mercosul. Diz a cláusula segunda do acordo que ele visa a ampliar a construção de uma base de entendimento comum que possa contribuir para solidificar os esforços de integração econômica e promover a formação e o aperfeiçoamento dos quadros docente e discente, além de estimular o desenvolvimento de pesquisa e extensão na área jurídica, no âmbito do MERCOSUL e Associados (STF, 2016).

Um segundo programa vinculado ao Fórum e ainda mais próximo das perspectivas do diálogo constitucional é aquele estipulado para promover a Cooperação e Intercâmbio de Magistrados e Servidores Judiciais do Mercosul e Associados, sendo o seu principal objetivo declarado o de "expandir as bases de cooperação judicial, o fortalecimento do bloco e a promoção da segurança jurídica na região, como fator de estabilidade política, econômica e social” (STF, 2016). Na prática, o programa consiste em intercâmbio de magistrados e funcionários dos poderes judiciários dos países envolvidos, permitindo que a interação perpasse o caráter objetivo das ferramentas de troca jurisprudencial e chegue ao nível das subjetividades atuantes.

\footnotetext{
4 A mencionada ferramenta está disponível no endereço eletrônico 〈http://www.cortesmercosul.jus.br/forum/jurisprudencia/pesquisarJurisprudencia.asp?tipo=M $>$, sendo que ali se pode pesquisar julgados constitucionais diretamente da Argentina, Bolívia, Brasil, Chile, Colômbia, Equador, Paraguai, Peru, Uruguai e Venezuela, sendo que, apesar de algumas falhas operacionais, é possível realizar buscas nos idiomas português, espanhol e inglês.

${ }^{5}<$ http://www.cortesmercosul.jus.br>
} 
Além da Conferência das Jurisdições Constitucionais dos Países de Língua Portuguesa e do Fórum de Cortes Supremas do Mercosul, uma importante iniciativa é a Conferência Ibero-americana de Justiça Constitucional ${ }^{6}$. Ela, à semelhança das demais, é antes de mais nada uma estratégia de integração. Foi criada em 1995, em Portugal, e conta hoje com a participação de Andorra, Argentina, Bolívia, Brasil, Chile, Colômbia, Costa Rica, Equador, El Salvador, Espanha, Guatemala, Honduras, México, Nicarágua, Panamá, Paraguai, Peru, Portugal, Puerto Rico, República Dominicana, Uruguai e Venezuela. Em seus Estatutos se lê que a:

[...] concertação e cooperação, assim como o diálogo entre as distintas instituições de justiça constitucional têm como objetivo último não só a melhoria e o aperfeiçoamento dos Tribunais, Cortes e Salas constitucionais, mas também contribuir com a reafirmação e consolidação dos princípios e valores do Estado de Direito, o correto funcionamento institucional dos poderes e uma maior eficácia e garantia dos direitos e liberdades da pessoa (CICJ, 2016).

Entre os principais objetivos da Conferência estão favorecer uma relação estreita, contínua e fluída entre os órgãos de justiça constitucional dos países Ibero-americanos; fomentar o intercâmbio de informação e a cooperação para consolidar a Comunidade Ibero- americana de justiça constitucional e promover a criação de redes para a gestão do conhecimento e o intercâmbio de experiências. A organização, apesar de não contar com um mecanismo centralizado de busca jurisprudencial, tem realizado desde a sua criação diversas reuniões, conferências e seminários sobre temas comuns, permitindo o aprofundamento de relevantes questões constitucionais como a tutela dos direitos fundamentais, as garantias e os limites constitucionais do poder sancionador do Estado e presidencialismo e parlamentarismos na jurisprudência constitucional. Na Declaração Final da Conferência, ocorrida em Cádiz, em maio de 2012, os representantes dos Tribunais presentes ressaltaram a importância do aporte de conteúdos ao sítio internet da entidade, favorecendo o intercâmbio de informações acerca das atividades de cada Corte.

A Comissão de Veneza ${ }^{7}$, que tem o nome de fundo de Comissão Européia para a Democracia através do Direito, é também integrada pelo Brasil, tendo sido originalmente concebida como órgão consultivo do Conselho da Europa em matérias constitucionais. Tratase de um conjunto de especialistas independentes nomeados para mandatos de quatro anos e

\footnotetext{
${ }^{6} \mathrm{Cf}$. http://www.cijc.org/Paginas/Default.aspx.

${ }^{7} \mathrm{Cf}$. http://www.venice.coe.int/WebForms/pages/?p=01_Presentation\&lang=EN
} 
que se reúnem na cidade italiana a fim de debater estudos e pareceres e divulgar sínteses acerca de soluções de problemas de âmbito constitucional. O principal veículo da Comissão é o Boletim de Jurisprudência Constitucional, editado periodicamente pelo Conselho de Justiça Constitucional, um sub-órgão da entidade. Neste Boletim é publicado um resumo de decisões relevantes das Cortes e Tribunais participantes (atualmente 60). Frequentemente são enviadas questões específicas às instâncias judiciárias nacionais a fim de obter um panorama abrangente do estado da arte de determinados temas constitucionais. Há também o CODICES, que é um banco de dados com mais de 7 mil textos completos de decisões de Tribunais Constitucionais. Como é dito expressamente no sítio da Comissão: "[e]stas publicações têm demonstrado um papel vital de 'fertilização cruzada' na jurisprudência constitucional" (COUNCIL OF EUROPE, 2016, tradução nossa), o que parece ser, exatamente, a ideia fundamental.

Com vínculo direto com a Comissão de Veneza tem-se a Conferência Mundial sobre Justiça Constitucional que se trata de um organismo que visa a integrar Tribunais Constitucionais e entidades de agregação de Cortes Supremas de todos os continentes, tão variados quando os seguintes: Tribunais Constitucionais Asiáticos, Associação dos Tribunais Constitucionais que utilizam a Língua Francesa, Tribunais da Commonwealth, Conferência dos Órgãos de Controle Constitucional dos Países de Jovem Democracia, Conferência dos Tribunais Constitucionais de Países de Língua Portuguesa, Conferência de Tribunais Constitucionais Europeus, Conferência Ibero-Americana de Justiça Constitucional, Fórum de Juízes-Presidentes da África Austral e União dos Tribunais e Conselhos Constitucionais Árabes. O primeiro dos objetivos constante no Estatuto da Conferência (COUNCIL OF EUROPE, 2016) é promover:

[...] a justiça constitucional - compreendida aqui no sentido do exame da constitucionalidade das leis, incluindo a jurisprudência dos direitos do homem - como elemento essencial da democracia, da proteção dos direitos do homem e do estado de direito.

Entre os principais meios pelos quais a organização visa alcançar seus objetivos, tem-se a organização de congressos que reúnam regularmente todos os membros em nível mundial; a participação em conferências e seminários regionais e a promoção do intercâmbio de experiências e de jurisprudência no seio dos grupos regionais e linguísticos, entre eles e com membros individuais. No primeiro Congresso da Conferência Mundial, ocorrido em 2009 na Cidade do Cabo, o tema principal foi 
[...] a influência da justiça constitucional na sociedade e a necessidade de desenvolvimento de uma jurisprudência global em direitos humanos. Representantes de 93 países debateram o uso de precedentes estrangeiros nas decisões das Cortes Supremas, a utilização de instrumentos de direitos humanos - tratados, convenções e a própria Declaração Universal de Direitos Humanos - como fundamento de suas decisões, o diálogo entre as cortes constitucionais e a possibilidade de uma convergência global das jurisprudências na área de direitos humanos (STF, 2016).

O segundo Congresso ocorreu no Rio de Janeiro, em 2011, sendo o tema principal “A separação de poderes e a independência dos tribunais constitucionais e órgãos equivalentes", com organização do STF. É notável, aliás, trecho da fala de abertura proferida pelo então presidente do Supremo Tribunal brasileiro e anfitrião, Cézar Peluso, que se opta por transcrever pela grande pertinência temática:

O aprofundamento das trocas entre os sistemas jurídicos é uma realidade do nosso tempo. Originalmente restritas aos limites do território soberano dos estados, as operações do mundo do direito estão se tornando cada vez mais transnacionais. Afora as evidentes implicações políticas, culturais, sociais e econômicas, o crescimento da interdependência entre as nações representa, agora, um duplo desafio aos judiciários nacionais. De um lado, a frequente interação com os sistemas regulatórios de outras nações. De outro, a necessidade de contruir pontes entre sistemas jurídicos autônomos, com a vontade de fortalecer e ampliar a cultura do estado de direito universal e da segurança jurídica como condições básicas do mundo civilizado e contínuo aprimoramento do espírito humano.

Estas pontes são materializadas de muitas formas: referências aos julgamentos estrangeiros em decisões de âmbito nacional, cooperação entre cortes e entre juízes, intercâmbios de professores e de profissionais do direito, interações com as cortes internacionais e numerosos outros mecanismos de comunicação. (COUNCIL OF EUROPE, 2016, tradução nossa).

Cabe referir, acerca de instrumentos de trabalho permanentes, que em ambas as edições do Congresso os Tribunais e Cortes participantes reforçaram o papel estratégico do Boletim e dos CODICES da Comissão de Veneza, seio de criação da Conferência.

No âmbito dos BRICS (grupo de países que congrega, em diversos níveis de cooperação, Brasil, Rússia, Índia, China e África do Sul) também se pode perceber uma consistente atuação conjunta de nível jurisdicional-constitucional. Entre os principais objetivos afirmados no Protocolo de Intenções, de 2009, que buscava criar o grupo, gizava-se a importância da troca efetiva de experiências para a modernização e aperfeiçoamento dos sistemas jurídicos dos países envolvidos (STF, 2016). Uma declaração firmada em 2009 entre os presidentes dos judiciários de Brasil, África do Sul e índia criando uma Conferência das 
Cortes Supremas do IBAS (sigla que resume a união dos três países), contudo essa iniciativa parece ter sido abarcada pela dos BRICS, posto que mais ampla e de comum desiderato. Isto pode ser visto na Declaração de Sanya, de 2011, fruto de reunião dos chefes de Estado e Governo dos cinco países membros do BRICS em que, entre outros temas, tratava de um novo protocolo de intenções entre as Supremas Cortes dos BRICS. Foi criado um banco de jurisprudência selecionada dos BRICS (STF, 2016) e um programa de intercâmbio de magistrados, que teve até então uma edição realizada no Brasil, em 2010.

A jurisprudência do STF está disponível, para além de todos os grupos e pactos de cooperação acima mencionados, no Portal Internacional (STF, 2016). Ao buscar-se a jurisprudência, tem-se a possibilidade de consultar, em inglês e espanhol, além da língua mãe, decisões do Tribunal e apontamentos da doutrina especializada sobre "questões constitucionais atuais e de interesse no cenário internacional.” Neste local, há links a bases de jurisprudência já referidas, como o Repositório de Jurisprudência Constitucional da CPLP e a jurisprudência selecionada dos BRICS. Chama a atenção, contudo, o texto de abertura do link para a base de dados dos CODICES da Comissão de Veneza. Ali se diz que:

[...] O Boletim de jurisprudência constitucional e a CODICES permitem a todas as pessoas interessadas de ter acesso a informações que até agora eram dificilmente acessíveis, senão a poliglotas que dispusessem de uma biblioteca especializada. Eles facilitam assim enormemente o trabalho comparativo dos operadores e lhes permite inspirar-se em soluções já utilizadas no estrangeiro, sobretudo em matéria de direitos fundamentais. As divergências jurisprudenciais entre Cortes constitucionais se devem cada vez mais a uma diferença de abordagem voluntária e não acidental. Assim, a circulação de informação é um potente motor do transconstitucionalismo, que permite às diversas cortes de se inspirarem na prática constitucional de seus pares. (COMISSÃO DE VENEZA, 2016, grifo nosso).

Vê-se que o conceito, nominado inclusive, do transconstitucionalismo está sendo incorporado institucionalmente pelo Supremo Tribunal Federal ao tratar da viabilização das trocas de experiências de resolução de problemas constitucionais concretos.

O STF está vinculado à GLIN - Global Legal Information Network ${ }^{8}$, que é um banco de dados online com decisões, legislação e literatura jurídica disponibilizado a todo o mundo. É uma colaboração entre diversos países do mundo por meio de órgãos públicos, não só judiciários, que transcendem, inclusive, a área constitucional.

\footnotetext{
${ }^{8}$ Cf. http://www.glinf.org/
} 
Vale dizer, por fim, que no dia 06 de abril de 2016, foi assinado memorando de entendimento entre o Conselho Nacional de Justiça e a Corte Interamericana de Direitos Humanos, por meio do qual as instituições garantiram a disponibilização do sítio eletrônico do Conselho da íntegra, em português, da jurisprudência da Corte. Em cerimônia de assinatura do entendimento, ocorrida naquela data, o presidente do STF, Ricardo Lewandowski, afirmou que "[a]s decisões da Corte IDH têm caráter vinculante, e o acesso a elas é um passo extraordinário para que os juízes tenham conhecimento do que faz esse órgão. " (CONSULTOR JURÍDICO, 2016). É mais um instrumento à disposição do diálogo transconstitucional.

\subsection{Dois casos de conflito}

O caso Julia Gomes Lund (Guerrilha do Araguaia), julgado em 2010 pela Corte Interamericana de Direitos Humanos - CIDH - abriu claro precedente de contradição entre o entendimento desta última e aquele esposado pelo Supremo Tribunal Federal brasileiro na Arguição de Descumprimento de Preceito Fundamental - ADPF - $\mathrm{n}^{\circ} 153$. Na ação que ainda tramita no STF, houve entendimento, por maioria, antes do julgamento da CIDH, de que a Lei de Anistia brasileira é constitucional, sendo aplicável inclusive aos agentes do Estado que perpetraram crimes e violações aos Direitos Humanos durante a Ditadura Militar. A CIDH, além de reconhecer a responsabilidade internacional do Brasil acerca de vários fatores de violação, diversamente, afirmou que a Lei de Anistia não pode ser alegada como impeditivo para a persecução penal daqueles que cometeram crimes em nome do Estado, mormente aqueles considerados contra a humanidade. É importante consignar que a ADPF $\mathrm{n}^{\mathrm{o}} 153$ pende de trânsito em julgado em virtude de recurso de embargos de declaração impetrado pela Ordem dos Advogados do Brasil, autora da arguição. Há, portanto, ao menos em tese, a possibilidade de mudança do entendimento do STF, mormente pelo considerável número de Ministros que deixou o Tribunal desde então.

O segundo caso a mencionar é o da Ação Penal no 470, do chamado mensalão, que teve rito originário no plenário do Supremo. Aqui a controvérsia transconstitucional ocorre em função de se ter como única instância a Corte Suprema ${ }^{9}$. Trata-se do visível conflito entre

\footnotetext{
${ }^{9}$ Como se pode ver na reportagem intitulada “Recurso à Corte Interamericana é 'o Direito de Espernear', diz ministro”, em que o Ministro Marco Aurélio, do STF, afirma que não há nenhuma possibilidade de o réu Valdemar Costa Neto obter tutela da Corte posto não ter havido violação a Direitos Humanos no julgamento, a seu ver. Relevante notar que na mesma reportagem consta o seguinte trecho: "Para Marco Aurélio Mello, ainda que o Brasil tenha apoiado e reconhecido a criação do tribunal internacional, as eventuais decisões da corte não têm o poder de cassar uma sentença da suprema corte brasileira." Disponível em <http://g1.globo.com/politica/mensalao/noticia/2012/10/recurso-corte-interamericana-e-o-direito-de-esperneardiz-ministro.html>, acesso em 28 de outubro de 2015.
} 
a alínea "h" do artigo oitavo da Convenção Americana de Direitos Humanos, que in litteris garante ao acusado de delito, entre outros, o "direito de recorrer da sentença para juiz ou tribunal superior".

É basicamente insustentável a tese de que tal garantia possa ser, em qualquer hipótese, afastada. Ainda que o chamado foro privilegiado, responsável, no caso de ações originárias no STF, pela instância única, seja pretensamente benéfico aos réus por trazer o tema ao mais alto colegiado judicial brasileiro, nada consta na Convenção que autorize a vedação do direito de recorrer. Difícil sustentar que os recursos de embargos infringentes, por seu turno, fariam as vezes de duplo grau ${ }^{10}$. Ademais, houve por parte de algumas defesas a tentativa de cindir a ação penal em relação aos réus que não detinham foro privilegiado, o que seria, portanto, uma renúncia do privilégio. Entretanto, o pedido foi negado pelos Ministros sob o argumento da necessária unicidade do julgamento, contrariando a jurisprudência recente do próprio STF.

Diante do fato das condenações, se está agora diante de caso quase inédito na história do STF, que basicamente não havia, com rara exceção, condenado originariamente detentor de foro privilegiado. A questão é que se dispõe de pouca jurisprudência internacional sobre o fato $^{11}$, permitindo supor que possa ser qualquer um o posicionamento do sistema interamericano de proteção dos Direitos Humanos: desde a chancela ao julgamento por 11 ministros da mais alta corte nacional sob o argumento de que ali se teve não apenas duas, mas mais de dez “instâncias" de julgamento; até a, não descartável hipótese, de que a Comissão e a Corte IDH, instadas, declarem que a prerrogativa de foro, quando originária no Tribunal Supremo, é inconvencional por afastar a garantia do duplo grau de jurisdição penal.

\footnotetext{
${ }^{10}$ Os recursos de embargos infringentes foram considerados aceitáveis pelo pleno do STF, em 18 de setembro de 2013, nos casos de réus do mensalão que tiveram no mínimo quatro votos favoráveis às suas teses no julgamento original. Houve quem argumentasse favoravelmente, como o caso do Min. Celso de Mello, à aceitabilidade dos recursos, entre outras, exatamente pela previsão do duplo grau obrigatório em matéria penal por força da Convenção Americana de Direitos Humanos. Contudo, pensamos, quando a norma internacional fala em "juiz ou tribunal superior", ela expressa, necessariamente, um outro órgão, jamais o que proferiu o julgamento recorrido.

${ }^{11}$ No caso Barreto Leiva, a Corte Interamericana de Direitos Humanos reconheceu a obrigatoriedade do duplo grau de jurisdição.
} 
No conflito que poderá redundar do recurso à CIDH dos condenados na Ação Penal n 470 do STF, parece que o Direito Internacional Público dispõe das ferramentas adequadas para a solução ${ }^{12}$. Dir-se-ia que o Brasil é soberano e, soberanamente, aderiu ao Pacto de SanJosé da Costa Rica, no qual, expressamente, consta o direito fundamental a todo o processado criminalmente de acessar, no mínimo, dois graus distintos de jurisdição em seu processamento penal. Neste caso, mandaria a CIDH que o Brasil observasse esse direito fundamental ao duplo grau de jurisdição e, com isso, o STF teria de aceitar recursos de $\operatorname{todos}^{13}$ os acusados (isso se o Brasil não fosse condenado, o que não é impossível, a criar nova sistemática de processamento originário de agentes com prerrogativa de função, posto que, atualmente, qualquer recurso de decisão originária do STF será ao próprio apresentado e não poderá ser julgado por qualquer instância outra que não o Supremo, o que, com precisão, jamais poderia se considerar como “outro" grau de jurisdição).

Tal como vão os ânimos do STF (manifestações públicas do ex-presidente da Corte, Joaquim Barbosa de não que não há possibilidade de os réus se queixarem, com êxito, à $\mathrm{CIDH}$, pois isso seria "enganar o público leigo" ${ }^{\text {, }}$ ), não é de se supor que o Direito Internacional, ainda que disponha, no caso, de mecanismos, teria império, pois a postura do STF é de que ele detém, inexoravelmente, a ultima ratio em toda e qualquer matéria que julgue. Não surpreenderia a suscitação de inconstitucionalidade do dispositivo da Convenção Americana de Direitos Humanos por parte de algum partido com representatividade no Congresso Nacional, e.g., e, ato contínuo, seu acatamento pelo STF. Aliás, esse parece, hoje, o desfecho mais provável, ainda que aqui figure, tão-somente, como conjectura.

\footnotetext{
12 Trecho de debates durante o julgamento da Ação Penal no 470 traz, da lavra do Min. Celso de Mello, a seguinte passagem, que demonstra a tese: "A questão central, neste tema, Senhor Relator, considerada a limitação da soberania dos Estados (com evidente afastamento das concepções de JEAN BODIN), notadamente em matéria de Direitos Humanos, e a voluntária adesão do Brasil a esses importantíssimos estatutos internacionais de proteção regional e global aos direitos básicos da pessoa humana, consiste em manter fidelidade aos compromissos que o Estado brasileiro assumiu na ordem internacional, eis que continua a prevalecer, ainda, o clássico dogma - reafirmado pelo Artigo 26 da Convenção de Viena sobre o Direito dos Tratados, hoje incorporada ao ordenamento interno de nosso País (Decreto $n^{o}$ 7.030/2009) -, segundo o qual 'pacta sunt servanda', vale dizer, 'Todo tratado em vigor obriga as partes e deve ser cumprido por elas de boa fé', sendolhe inoponíveis, consoante diretriz fundada no Artigo 27 dessa mesma Convenção de Viena, as disposições do direito interno do Estado nacional, que não poderá justificar, com base em tais regras domésticas, o inadimplemento de suas obrigações convencionais, sob pena de cometer grave ilícito internacional. Não custa relembrar que o Brasil, apoiando-se em soberana deliberação, submeteu-se à jurisdição contenciosa da Corte Interamericana de Direitos Humanos, o que significa, considerado o formal reconhecimento, por parte de nosso País, da competência da Corte (Decreto $\left.n^{\circ} 4.463 / 2002\right)$, que o Estado brasileiro comprometeu-se, por efeito de sua própria vontade político-jurídica, 'a cumprir a decisão da Corte em todo caso' de que é parte (Pacto de São José da Costa Rica, Artigo 68). 'Pacta sunt servanda'..."

${ }^{13}$ Não apenas daqueles que se enquadram na apertada hipótese dos "embargos infringentes".

${ }^{14} \mathrm{Cf}$. artigo de Luiz Flávio Gomes em <http://www.adufal.org.br/site/mostranoticia. aspx?cod=9438>
} 
Quanto pior não é, portanto, a situação da oposição entre o STF e a CIDH no caso Gomes Lund, pois nele já se tem a contradição instalada. Os mesmos dispositivos de Direito Internacional supra mencionados poderiam aqui se mencionar para sustentar a prevalência do que julgou a Corte Interamericana de Direitos Humanos, contudo, ainda que superveniente a decisão desta, no que pertine às obrigações ajustadas no dispositivo ao Poder Judiciário brasileiro, nada se pode considerar cumprido. De todos os mandamentos, se nos parece o maisimportante aquele que diz que o Brasil não poderá basear-se em sua Lei de Anistia para evitar a persecução penal daqueles que cometeram crimes contra a humanidade no período da ditadura milita. Ora, se também é preceito de Direito Internacional dos Direitos Humanos que a lei penal não retroagirá, então não se pode cogitar de alteração in pejus da Lei de Anistia pela via legislativa, restando, apenas, a via judicial a considerá-la, na parte que alguns supõem anistiar também os torturadores e criminosos de Estado em geral, inaplicável pelo evidente descumprimento de preceito fundamental e pela inconstitucionalidade frente à Carta Democrática de 1988. É o que se pretendia com a ADPF no 153 (e ainda se pretende, frente o não trânsito em julgado).

Em ambos estes casos, como se depreende, a sistemática transconstitucional poderia ser o esteio de soluções mais equilibradas, justas e, sobretudo, efetivas. Não será benéfico para ninguém se a opinião de qualquer das instâncias for sumariamente excluída do âmbito de validade pela outra. De nada valerá decisões magistrais da CIDH se o STF as desconsiderar, tampouco servindo plenamente as deste último se redundarem na responsabilidade internacional do Brasil perante os demais países. Fica evidente que a racionalidade transversal em muito contribuiria na solução dos conflitos, seja pela enfrentamento dos argumentos de divergência atuais, seja pela consideração do que o planeta já desenvolveu em matéria de duplo grau de jurisdição penal e de justiça transicional, ambas experiências constitucionais ricas e capazes de proporcionar melhores e mais legítimas soluções.

\section{CONCLUSÃO: OS SUPREMOS EXTREMOS}

Se o transconstitucionalismo resume-se a um movimento bem intencionado de juristas juízes e não juízes que querem aprender com as experiências dos outros, ou se há alguma forma de tornar este um movimento inexorável e forte na integração do sistema parcial jurídico de nível mundial, é algo que exigiria esforço argumentativo e de pesquisa infinitamente maior do que os limites aqui impostos. 
Perfilamo-nos com os que entendem que, atualmente, o diálogo transconstitucional é a um tempo (1) constatação fática de um movimento que realmente está acontecendo e decorre de fatores tão diversos quanto, e.g., o realinhamento político-econômico num sistema-mundo efetivamente multipolar que ora brota e o avanço de uma teia de comunicações eletrônicas de nível planetário; e (2) oportunidade real para miríades de juristas (e por que não políticos e sociólogos?) que buscam, com a premissa de que não há resposta certa, mas apenas respostas boas ou possíveis, encontrar soluções a problemas complexos, em culturas diferentes, mas sempre animados pela efetividades dos direitos humanos. No limite, é um non sense criticar alguém por ser "bem intencionado", dado que o oposto disso é a ardilosidade e a fraude.

Independentemente da conclusão a que se chegasse sobre as hipóteses acima, parece demonstrado que o Brasil conta atualmente com relevantes mecanismos institucionais, disponibilizados pelo Supremo Tribunal Federal, para tanto a divulgação de nossa cultura de julgados constitucionais, quanto para absorver, de todos os quadrantes do mundo, soluções jurídicas para problemas de direitos humanos e liberdades individuais conforme já vêm sendo resolvidos por outros povos.

Não obstante, para se suplantar honestamente o mero uso reforçativo de jurisprudências internacionais em decisões pré-concebidas e viabilizar efetivas correntes de diálogo, pontes de transição ou linhas de racionalidade transversal capazes de aportar um ambiente de conversação constitucional efetiva, faz-se necessário avançar das posições protecionistas e enclausurantes tais como vêm sendo proferidas por alguns dos ministros do STF em falas externas aos julgamentos. Não há hierarquia, por certo, entre a Corte Interamericana de Direitos Humanos, e.g., e o Supremo Tribunal Federal, mas também não pode haver rechaço unilateral. Duas oportunidades, (ADPF no 153 e AP n ${ }^{\circ}$ 470) são relevantes e notórios exemplos que tem o STF para buscar nos fundamentos decisórios da CIDH argumentos a ser destacados para melhorar e/ou mesmo reforçar suas posições. O que parece não lhe ser mais dado, até mesmo pela força de suas próprias iniciativas institucionais, é desconhecer tão solenemente, como vem fazendo, aquilo que o mundo lhe oferece. 


\section{REFERÊNCIAS}

CANOTILHO, J. J. Gomes. "Brancosos" e Interconstitucionalidade: Itinerários dos Discursos Sobre a Historicidade Constitucional. 2a Ed. Coimbra: Almedina, 2008. 2003. . Direito Constitucional e Teoria da Constituição. $7^{\mathrm{a}}$ Ed. Coimbra: Almedina,

CONFERENCIA IBERO-AMERICANA DE JUSTIÇA CONSTITUCIONAL. Estatutos. Disponível em: 〈http://www.cijc.org/acercaCIJC/es-ES/Documentacin/Estatutos.pdf>, acesso em: 04 de abril de 2016.

CONSULTOR JURÍDICO. CNJ divulgará em seu site jurisprudência em português de corte interamericana. Disponível em <http://www.conjur.com.br/2016-abr-06/cnj-divulgarajurisprudencia-portugues-corte-interamericana>, acesso em: 11 de abril de 2016.

COSTA, Fábio; OLIVEIRA, Mariana; PASSARINH, Nathália. Recurso à Corte Interamericana é o direito de espernear, diz Ministro. Disponível em:< http://g1.globo.com/politica/mensalao/noticia/2012/10/recurso-corte-interamericana-e-odireito-de-espernear-diz-ministro.html> Acesso em: 04 de abril de 2016.

COUNCIL OF EUROPE. Speech of Justice Cezar Peluso on 2 nd Congress of the World Conference on Constitutional Justice. Disponível em:

http://www.venice.coe.int/WCCJ/Rio/Papers/BRA_Peluso_opening_E.pdf. Acesso em: 04 de abril de 2016.

\section{. CODICES. Disponível}

em: $<$ http://www.codices.coe.int/NXT/gateway.dll?f=templates\&fn=default.htm $>$ Acesso em: 04 de abril de 2016.

. Estatutos da Conferência Mundial de Justiça constitucional. Disponível em:

http://www.venice.coe.int/WebForms/pages/?p=02_WCCJ\&lang=EN Acesso em: 04 de abril de 2016.

GOMES, Luiz Flávio. Celso de Mello diz que Joaquim Barbosa (o herói nacional) está errado. Disponível em: <http://www.adufal.org.br/site/mostranoticia.aspx? cod=9438>Acesso em: 04 de abril de 2016.

HÄBERLE, Peter. Estado Constitucional Cooperativo. Rio de Janeiro: Renovar, 2007.

. El estado constitucional. Tradução de Hector Fix-Fierro. México: Universidad Nacional Autónoma de México, 2003.

. Pluralismo y Constitución. Estudios de Teoría Constitucional de la sociedad abierta. Madrid: Tecnos, 2002.

. Hermenêutica constitucional. Sociedade aberta de intérpretes da Constituição: contribuição para a interpretação pluralista e procedimental da Constituição. Tradução de Gilmar Ferreira Mendes. Porto Alegre: Sérgio Fabris, 1997. 
HERRERA FLORES, Joaquin. A reinvenção dos direitos humanos. Florianópolis: Fundação Boiteaux, 2009.

Teoria crítica dos Direitos Humanos. Os direitos humanos como produtos culturais. Rios de Janeiro: Lúmen Júris, 2008.

NEVES, Marcelo. Transconstitucionalismo. São Paulo: WMF Martins Fontes, 2009.

PIOVESAN, Flávia. Direitos Humanos e o Direito Constitucional Internacional. $12^{\mathrm{a}}$ ed. São Paulo: Saraiva, 2011.

. Direitos Humanos e Justiça Internacional. São Paulo: Saraiva, 2006.

SUPREMO TRIBUNAL FEDERAL. Acordo de Cooperação que celebram entre si os Tribunais e Cortes Supremas do Mercosul e associados para o intercâmbio de informações através da utilização de um banco de dados de jurisprudência do Mercosul. Disponível em: < http://www.stf.jus.br/arquivo/cms/forumCorteSupremaDocumento/forumCorteSupremaDoc umento_AP_77764.pdf> Acesso em: 04 de abril de 2016.

em:

. Conferência Mundial: primeiro encontro ocorreu na Cidade do Cabo. Disponível

<http://www.stf.jus.br/portal/cms/verNoticiaDetalhe.asp?idConteudo=169463\&caixaBusca= $\underline{\mathrm{N}>}$ Acesso em: 04 de abril de 2016.

. Protocolo de intenções. Disponível em:

$<$ http://www.stf.jus.br/repositorio/cms/portalStfInternacional/portalStfCooperacao_pt_br/anex o/2009.09.29.Prot._Intencoes_BRIC_Brasil.PDF> Acesso em: 04 de abril de 2016.

. Cooperação Internacional. Disponível em:

<http://www2.stf.jus.br/portalStfInternacional/cms/verConteudo.php?sigla=portalStfCooperac ao_pt br\&idConteudo=159656> Acesso em: 04 de abril de 2016.

. Regimento Interno Forum de Cortes Supremas. Disponível em:

<http://www.stf.jus.br//arquivo/cms/forumCorteSupremaDocumento/forumCorteSupremaDoc umento_AP 75300.pdf> Acesso em: 04 de abril de 2016.

Estatutos. Conferência das Jurisdições Constitucionais dos Países de Língua

Portuguesa. Disponível em: <http://www2.stf.jus.br/cjcplp/cjcplp_estatutos.html > acesso em: 04 de abril de 2016.

. Programas de cooperação Internacional. Disponível em:

<http://www2.stf.jus.br/portalStfInternacional/cms/verConteudo.php?sigla=portalStfCooperac ao_pt_br>. Acesso em: 04 de abril de 2016.

VENTURA, Deisy As assimetrias entre a União Européia e o Mercosul. Os desafios de uma associação inter-regional. São Paulo: Manole, 2003.

ZOLO, Danilo. Cosmópolis. Perspectiva y riesgos de un gobierno mundial. Buenos Aires: Paidós, 2000. 